\title{
Cross-national gender differences in the socioeconomic factors associated with smoking in Australia, the United States of America and South Korea
}

\author{
Davina J. French ${ }^{1}$ \\ Soong-nang Jang ${ }^{2}$ \\ Robert J. Tait ${ }^{1,3}$ \\ Kaarin J. Anstey ${ }^{1}$ \\ ${ }^{1}$ Centre for Research on Ageing, Health and Wellbeing, Australian National University, \\ Canberra, Australia \\ 2 Department of Nursing, Chung-Ang University, Seoul, Republic of Korea \\ ${ }^{3}$ Centre for Mental Health Research, Australian National University, Canberra, Australia
}

\section{Corresponding Author}

Davina French

Centre for Research on Ageing, Health and Wellbeing,

Australian National University,

Canberra, ACT 0200

Australia

Telephone: 61 (0)2 61259180

Fax: 61 (0)2 61251558

Davina.french@anu.edu.au 


\section{Abstract}

Objectives We compared rates of smoking among those aged 45 years and older in Australia, the United States of America and South Korea, and examined cross-national gender differences in key socioeconomic differentials in smoking.

Methods We conducted weighted analyses on cross-sectional data from nationally representative surveys conducted in 2006.

Results Current smoking was more prevalent for males than females in all countries; the gender difference was largest in Korea. Being unpartnered increased the likelihood of smoking in all countries, while greater wealth reduced it. In Korea these effects interacted with gender; both indicators showed larger differentials among women than men. Lower educational attainment increased the likelihood of smoking for all groups except Korean women, among whom high school educated women were less likely to smoke than the tertiary educated.

Conclusions Our findings support a cultural interpretation of gender differences in smoking: in countries with low gender empowerment, gender differences in smoking are greater. With increasing divorce and female tertiary education rates in nations like Korea, we highlight the need for health promotion messages targeted towards older and more educated women.

Keywords

Smoking; older adults; gender differences; Australia; United States of America; South Korea 


\section{Introduction}

Tobacco consumption is detrimental for health and even light smoking has adverse health consequences (Bjartveit \& Tverdal, 2003; Prescott, Scharling, Osler, \& Schnohr, 2002; U.S. Dept. of Health and Human Services, 2004). Tobacco use is predicted to result in one billion deaths during the $21^{\text {st }}$ century if behavior does not change (World Health Organization, 2011b). National and international health authorities therefore recommend complete abstinence from tobacco. Nevertheless, a significant proportion of the world's population continues to smoke, although there is considerable variation in smoking prevalence both between and within nations. This study explores factors underlying smoking behaviour by investigating its correlates from a cross-national perspective. Expanding upon studies that have used national-level indicators to investigate cultural and economic factors associated with gender differences in smoking prevalence (Hitchman \& Fong, 2011; Pampel, 2006), we examined the socioeconomic correlates of smoking for men and women within nations to further understand cross-national differences in smoking patterns.

Gender differences in smoking vary between countries for a number of reasons (Pampel, 2006), including their progression through the 'cigarette epidemic' (Lopez, Collishaw, \& Piha, 1994). This model describes a large gender difference in the early decades of smoking uptake, as men become smokers while women remain constrained by cultural and socioeconomic factors (Pampel, 2006). Women’s rates then increase as smoking becomes commonplace, and in the late stages of the 'epidemic' the gender difference narrows further as tobacco control measures reduce smoking for both sexes (Lopez, et al., 1994). While time since smoking introduction may explain some gender differences, research in Asia has suggested that epidemic theory is a poor fit for the patterns observed there. Cultural differences in women's empowerment also influence smoking behavior (Hitchman \& Fong, 2011; Pampel, 2006), and stronger cultural pressures may be at work in some countries, resulting in different patterns of gender difference over time and between socioeconomic groups (Kim, Son, \& Nam, 2005).

Smoking is generally associated with socioeconomic disadvantage (Banks, Marmot, Oldfield, \& Smith, 2006) and with not being married (Schone \& Weinick, 1998). These differentials however vary with age and gender, for example a large European study found that the effect of educational inequality was reversed in older women; those with more education were more likely to have ever smoked, perhaps reflecting their increased independence relative to other women in their cohort (Schaap, et al., 2009). The protective 
effect of being married did not differ between men and women in a European sample, but a gender difference has been observed in Asia (Cho, Khang, Jun, \& Kawachi, 2008; Sulander, Helakorpi, Rahkonen, Nissinen, \& Uutela, 2004). Understanding the links between gender and other socio-demographic indicators, and how these vary cross-nationally, can inform tobacco control measures by illuminating some of the social dynamics underlying gender differences in smoking prevalence.

This paper compares the socioeconomic correlates of smoking in middle-aged and older men and women in three countries with similar levels of development (all are high income, very highly developed nations) but different levels of gender empowerment (United Nations Development Programme, 2009). Gender empowerment was operationalised as the Gender Empowerment Measure (GEM), which describes gender inequality in terms of political and economic participation (United Nations Development Programme, 2009).

Australia and the United States of America (USA) have had social policies to promote gender equality for more than forty years. Both countries are now in Stage IV of the 'cigarette epidemic', when smoking is seen as socially abnormal and gender differences are likely to be small although socioeconomic differentials are large (Lopez, et al., 1994). Australia remains at the forefront of tobacco control enforcement through the proposed introduction of plain cigarette packaging (World Health Organization, 2011b). The Republic of Korea (hereafter Korea) has developed rapidly and became the world's fastest growing economy in the late $20^{\text {th }}$ century. Life expectancy at birth now exceeds the USA (United Nations Population Division, 2011) and Korean GDP ranks $14^{\text {th }}$ in the world compared to Australia's $15^{\text {th }}$ (World Bank, 2011). The position of women in Korean society, however, lags behind other socioeconomic indicators, with GEM ranked $61^{\text {st }}$ among 109 countries compared to Australia's $7^{\text {th }}$ and the USA's $18^{\text {th }}$ (United Nations Development Programme, 2009).

Korea's enactment of tobacco control measures has been relatively recent and smoking rates are now falling (Park, et al., 2009). There are however strong cultural norms surrounding cigarette use; for men, smoking is important for social conformity and the offering and acceptance of cigarettes is a central ritual in social and business settings. In contrast, smoking is regarded as contrary to women's traditional roles as wife and mother (Kim, et al., 2005).

We report rates of smoking for middle-aged and older men and women in these three nations and examine the socioeconomic risk differentials for smoking by country and gender. In line with recently reported data (World Health Organization, 2011a) we expect larger 
gender differences in Korea than Australia and the USA. We also predict that socioeconomic disadvantage will be associated with increased likelihood of smoking in all three countries, since tobacco control measures are likely to have had their greatest influence among socially advantaged individuals. Since smoking is also likely to be influenced by health status and related to alcohol consumption, these are included as covariates in all analyses. Our key research focus is upon how socioeconomic factors interact with gender. Such interactions could further illuminate the social and cultural factors that influence decisions to smoke.

\section{Method}

\section{Samples}

Data were drawn from nationally representative surveys conducted in 2006. Responses from people aged 45 years and older were selected for analysis. Each of the original studies received appropriate ethical approvals; our study analysed only de-identified data files, which were used with permission.

\section{Australia}

The Australian sample was drawn from wave 6 of the Household, Income and Labour Dynamics in Australia (HILDA) survey, a household-based panel study with annual data collection. All adult household members take part in a face-to-face interview followed by a written questionnaire. The response rate at wave 1 was $66 \%$ of eligible households (Wooden, Freidin, \& Watson, 2002) with 76.2\% of these respondents re-interviewed at wave 6 (Melbourne Institute of Applied Economic and Social Research, 2008). All respondents aged 45 years and older were included in our analyses.

\section{United States of America}

The USA sample was drawn from wave 8 of the Health and Retirement Study (HRS; (Health and Retirement Study, 2008b). HRS is a nationally representative survey of older Americans sponsored by the National Institute of Aging (grant number NIA U01AG009740) and has been conducted by the University of Michigan every two years since 1992 with periodic addition of younger cohorts. Response rates range from 86-89\% across waves with wave-towave retention better than 90\% (Health and Retirement Study, 2008a). Data are collected by computer assisted interview; these are mainly by telephone but face-to-face interviews are preferred for the oldest respondents. In 2006, targeted respondents were aged 53 years and 
over and their spouses were also interviewed regardless of age. To maintain comparability we excluded a small number $(0.8 \%)$ of spouses aged below 45 years.

\section{Korea}

Data for the Korean sample were drawn from the first wave of the Korean Longitudinal Study of Ageing (KLoSA), conducted by the Korea Labour Institute. The household response rate of $70.7 \%$ at wave 1 compares favourably with HILDA (Korea Labor Institute, 2007). The KLoSA sample represents the population 45 years and older and was designed to be comparable with similar panel studies in other countries such as HRS. The KLoSA survey instrument was administered with computer assistance during a face-to-face interview.

\section{Materials and data harmonisation}

\section{Smoking}

Australian participants reported their smoking status as 'never smoker', 'former smoker' or 'current smoker' and the Korean sample was asked 'have you ever smoked cigarettes?' and ‘do you smoke cigarettes now?' In HRS the question 'have you ever smoked cigarettes?' was asked in earlier surveys. This information was carried forward and used in conjunction with responses to the question 'do you smoke cigarettes now?'. In order to replicate the proposed analyses across countries, we collapsed never and former smokers to become 'non-smokers' since the low proportion of female former smokers in Korea $(<1 \%)$ prevented analysis of this category separately.

\section{Socio-demographic information}

Age and sex were available in all datasets. Information on current marital status was harmonised to produce a binary variable labelled 'partner status', denoting whether the respondent was currently living with a partner or not. Educational attainment was recorded using different but partially overlapping response options in the three countries, which reflected their somewhat different educational systems. We used a harmonised four category variable of 'primary school or less', 'high school', 'some post-secondary education', for example a diploma, and 'completed degree' at a tertiary level. Net wealth was calculated as total household assets minus debts, divided by square root of household size to adjust for household size (Organisation for Economic Co-operation and Development, 2008a) and adjusted for purchasing power parity (PPP) for Australia and Korea using 2006 exchange rates (Organisation for Economic Co-operation and Development, 2008b). To facilitate 
comparison of the odds ratios for wealth with the other variables, it was entered into regression analyses as quintiles.

\section{Self-rated health}

All three surveys measured self-rated health (SRH) on a five-point Likert scale ranging from 'excellent' to 'poor'; HRS asked 'would you say your health is...' while HILDA and KLoSA asked 'In general, would you say your health is...'. Those reporting excellent or very good health were combined and compared to those reporting good, fair or poor health.

\section{Alcohol consumption}

All respondents were asked whether they ever drank alcohol. Those who responded 'no' were classified as non-drinkers. For the remaining respondents frequency and quantity of drinking were available reflecting, on average, how many days each week alcohol was consumed and typical number of drinks per occasion. National guidelines differ on what level of consumption is safe for whom, and on the alcohol content of 'standard' drinks. We converted the Australian and Korean data to USA standard drinks containing 14g of ethanol (National Institute on Alcohol Abuse and Alcoholism, 2008) and multiplied quantity by frequency to estimate typical number of drinks per week. Respondents were then categorized as nondrinkers, light drinkers (no more than 7 drinks/week), moderate drinkers (7 up to 14 drinks/week) and at-risk drinkers (more than 14 drinks/week). More than 14 drinks per week exceeds guidelines for safe drinking in both the USA and Australia (National Health and Medical Research Council, 2009; National Institute on Alcohol Abuse and Alcoholism, 2008).

\section{Statistical analysis}

Analyses were corrected for clustering within households since sampling was at the household level in all three surveys. Cluster corrections and individual sampling weights were applied using the Complex Samples facility in PASW Statistics 19.0. Logistic regression analyses examined indicators of increased likelihood of current smoking in each country. Independent variables were age, gender, wealth, marital status, education, and selfrated health. Age and wealth were treated as continuous covariates, for the remaining variables the reference groups were female, currently partnered, light drinker and the highest categories of educational attainment and self-rated health. To examine our key research question we tested interactions between gender and the key social and economic associates of 
current smoking: wealth, marital status and education. Significant interactions were further explored by repeating the analyses separately for men and women to compare the odds ratios obtained.

\section{Results}

\section{Sample characteristics}

Sample characteristics are shown in table 1. All characteristics varied between countries, with the USA sample being significantly older and the Korean sample reporting significantly lower educational attainment and poorer health. Rates of at-risk drinking were highest among Korean males and lowest among Korean females. Net wealth was lower in Korea even after adjustment for PPP and was lower for females in all three countries.

\section{Smoking prevalence}

Table 2 shows smoking prevalence by gender and age group for each country and includes comparison values from recent World Health Organisation estimates of smoking prevalence for these countries (World Health Organization, 2011a). The proportion of current smokers was higher among males than females in all three countries, and highest among Korean males. In all three countries prevalence among our middle-aged and older samples was lower than national estimates.

\section{Socioeconomic differentials in smoking in Australia, the USA and Korea}

Table 3 shows the results of the regression analyses for current smoking in each country. This confirms the magnitude of the difference in the gender effect in Korea compared to the other two countries, where odds ratios of less than two were obtained compared with 22.68 in Korea. Those who were older or had greater wealth were less likely to be current smokers in all countries. Those not currently living with a partner (single, widowed or divorced) were more likely to smoke, as were those with lower levels of educational attainment compared with the tertiary educated. Moderate and at-risk drinkers were more likely to be smokers, and in Korea only abstainers were less likely to smoke. Current smoking was more closely related to SRH in Australia and the USA than in Korea.

Interactions with gender were only significant in Korea; significant interactions were found between gender and wealth $(p<.001)$, education $(p=.001)$ and partner status $(p<$ $.01)$. Table 4 shows the odds ratios for current smoking for men and women in Korea. Being 
unpartnered and less wealthy increased the likelihood of smoking somewhat more for Korean women than for men; for example, the proportion of unpartnered women who smoked was 3.3 times greater than for partnered women, where for men the ratio was 1.3:1. The increased likelihood of smoking among the less educated was not apparent for Korean women; those with a high school education were less likely to smoke than those with a tertiary degree.

\section{Discussion}

\section{Smoking in Australia, the USA and Korea}

Males in our study were more likely to smoke than females and smoking was more prevalent in younger than in older age groups. Consistent with their differing GEM rankings, the gender difference in smoking in Korea was much larger than in Australia and the USA. This is consistent with previous findings (Y. H. Khang \& Cho, 2006) and with a cultural explanation of gender differences in Korea, rather than with the cigarette epidemic. Also consistent with data previously published for those aged up to 74 years (Cho, et al., 2008), current smoking was higher among the older Korean women in our sample.

We found that smoking had a similar association with socioeconomic characteristics across nations with different historical and cultural backgrounds. In general, higher rates were associated with lower levels of education and wealth and with being unpartnered. The stronger association of smoking with poor self-reported health in Australia and the USA may reflect greater internalization of health promotion messages in these countries following a longer period of anti-smoking campaigns.

\section{Cross-national gender differences in socioeconomic differentials of smoking}

Socioeconomic differentials in smoking interacted with gender only in Korea. The effect of being without a partner, which increased the likelihood of smoking, was larger for women. This finding extends to older Koreans previous reports of a gender difference in the association of marriage with smoking in those aged under 75 years (Cho, et al., 2008). Our data showing increased smoking among older and unpartnered Korean women may indicate that not holding the traditional roles of wife and mother, either through singlehood or being widowed, permits women to take up smoking. Alternatively, smoking may be under-reported by married women due to the stigma associated with it (Wewers, et al., 1995). Wealthy Korean women were less likely to be smokers, with wealth having a larger protective effect than was observed among Korean men or in the Australian and USA samples. 
Lower educational attainment was associated with increased likelihood of smoking only for Korean men; high school educated older women in Korea were less likely to be smokers compared with tertiary educated women. Recently published differentials for smoking among Korean adults aged 25-64 years suggest that socioeconomic disparities in smoking occur in both sexes in this younger age group (Y.-H. Khang, Yun, Cho, \& JungChoi, 2009), however a reversal of the usually protective effect of education among older women has also been noted in Europe (Schaap, et al., 2009). These authors suggested that more highly educated women might have been able to take up smoking at an earlier stage of the cigarette epidemic since they had more resources and perhaps more personal freedom.

In Korea highly educated women may also experience more freedom from the constraints of traditional gender roles, especially as they become older, thus increasing their likelihood of current smoking despite the emergence of health promotion strategies in that country. It should be noted, however, that only $6 \%$ of older Korean women had attained postschool qualifications in our data; as well as being few in number, they may be unrepresentative of the larger proportion of women who are currently gaining a tertiary education. Although it is not clear whether the higher rates of smoking among tertiary educated women will be observed in the next cohorts as they age, the proportion of enrolled tertiary students who are female has risen to $37 \%$ in Korea in the $21^{\text {st }}$ century (United Nations Statistics Division, 2007), making further investigation of their health behavior an urgent priority.

\section{Implications}

In Australia, there has been some success in reducing the general prevalence of smoking. Yet, from our data, between one quarter and one fifth of those aged 45-54 are still smokers. In those aged over 60 there has been no decline in the prevalence of smoking in recent years (Scollo \& Winstanley, 2008), and many anti-smoking messages are focused on prevention in young people. The proposed 'plain packaging' legislation should, however, provide further impetus to cessation efforts in Australia. Similarly, in the USA, although there has been a general decline in the prevalence of smoking, this has stalled in recent years, with tobacco control programs currently receiving less than 3\% of the revenue raised from tobacco (Dube, Asman, Malarcher, \& Carabollo, 2009). Although well into Stage IV of the smoking epidemic, it is important that these nations continue to promote tobacco control and consider older as well as younger adults when framing their campaigns. 
Our analyses showed that $42.7 \%$ of older Korean males are current smokers. Although prevalence has fallen over the past two decades, from almost $70 \%$ for this age group in 1992, it remains high by international standards (Park, et al., 2009). Park and colleagues also observed a steeper decline in smoking rates among older men over this period, and suggested that it may be associated with poor health (Park, et al., 2009). Population ageing is occurring more rapidly in Korea than in the USA or Australia, with $41 \%$ of the population expected to be over 60 years of age by 2050 (United Nations Population Division, 2010). Understanding the changing social and cultural influences on risky behaviors in Korea is therefore of critical importance in order to reduce factors that may further exacerbate the health burden of this ageing population. Our observation that smoking is associated with social and cultural as well as health indicators may be helpful in designing future anti-smoking campaigns.

As Korea modernizes, its growing numbers of educated women may be less constrained by gender norms than their mothers and grandmothers. The clearest correlates of smoking for these older women were family-level factors (marriage and household income), but future generations may experience more independence from family expectations. Divorce rates are also rising rapidly in Korea, especially among younger couples (Lee, 2004). Cultural expectations of marriage and motherhood may not afford the same protection against risky behaviors for future generations of Korean women that we see in our sample. Tobacco control measures in Korea should therefore also address women, despite their currently low rates of smoking.

Although describing alcohol consumption was not the primary purpose of this report, information used as a control variable in the regression analyses revealed that alcohol consumption among middle aged and older adults should also be a cause for concern. In Australia and Korea a considerable number of men were found to be drinking at risky levels (more than 15\% and 19\% respectively). Our earlier discussions of the need to address unhealthy behavior among Korean men and the age appropriateness of current health promotion messages might be extended to target unsafe drinking

\section{Limitations}

Former smokers and never smokers may differ both psychologically and in their physical health. However, the prevalence of former smoking in Korean women was very low; among these women $99.5 \%$ of non-smokers were never smokers. Since our primary purpose was to report the same analyses across countries, we were unable to investigate the differences 
between former smokers and never smokers because of the very small number of female Korean former smokers. We acknowledge that this may leave important differences unexplored in the Australian and U.S. samples.

We also acknowledge that survival effects inherent in these datasets may compromise our conclusions. Our prevalence estimates for smoking among older cohorts probably underestimate the proportions of these cohorts who were once smokers, since some smokers will have died prematurely, and those who remain are likely to be healthier than 'typical' smokers. Cohort studies also tend to underestimate smoking prevalence due to non-response bias, although estimates for the associations between variables are less likely to be affected (Van Loon, Tijhuis, Picavet, Surtees, \& Ormel, 2003).

The needs of data harmonization prevented disaggregation of demographic and socioeconomic indicators at a finer level of detail, for example, the binary partner status variable showed that people not currently living with a partner were more likely to be smokers, but we could not establish whether this was equally true for those widowed, divorced and never married. We have also discussed above the possibility that stigma associated with female smoking may have influenced Korean women’s reports, perhaps particularly those of married women.

We also note that all three of the datasets employed in this study used samples recruited at the household level; that is, they included husbands and wives where both were alive and consented. Health behaviors such as smoking and attempting to quit are generally concordant within marital dyads (Meyler, Stimpson, \& Peek, 2007), although the studies examining this have been conducted predominantly in the USA. Our analyses employed corrections for household level clustering, but this cannot rule out the possibility of different kinds of dyadic influence between countries, indeed this is an issue that our data suggest might be a fertile avenue for further investigation.

\section{Conclusion}

In order to understand the social, cultural and economic influences on smoking behavior, it is important to study predictor variables at both individual and national levels. Our crossnational study complements previous studies that have employed national-level indicators to investigate gender differences in smoking prevalence (Hitchman \& Fong, 2011; Pampel, 2006), and reveals some of the social dynamics that may explain gender differences in smoking in a nation with low gender empowerment. Our findings regarding the prevalence of 
smoking among middle-aged and older adults also highlight the need for targeted health promotion efforts for this sector of the population.

\section{Ethical standards}

Each of the original studies included in this paper received appropriate institutional ethical approvals. Our study analysed only de-identified data files, which did not require ethical approval. De-identified data were obtained and used with permission through registration with the appropriate organizations.

\section{Conflict of interest}

The authors declare that they have no conflict of interest.

\section{Acknowledgements}

This paper uses unit record data of the Household, Income and Labour Dynamics in Australia (HILDA) Survey. The HILDA Project was initiated and is funded by the Australian Government Department of Families, Housing, Community Services and Indigenous Affairs (FaHCSIA) and is managed by the Melbourne Institute of Applied Economic and Social Research (Melbourne Institute). The findings and views reported in this paper, however, are those of the author and should not be attributed to either FaHCSIA or the Melbourne Institute. Data from wave 8 of the Health and Retirement Study (HRS) are used with permission. HRS is sponsored by the National Institute of Aging (grant number NIA U01AG009740) and conducted by the University of Michigan. Data from the Korean Longitudinal Study of Ageing (KLoSA) are used with permission. KloSA is conducted by the Korean Labor Institute and funded by the Korean Ministry of Labor through the Employment Insurance Fund. This research was supported by a grant from the Australian Research Council Centre for Excellence in Population Ageing Research (CEPAR) and by National Health \& Medical Research Council Research Fellowship No. 366756 to the last author. 


\section{References}

Banks, J., Marmot, M., Oldfield, Z., \& Smith, J. P. (2006). Disease and disadvantage in the United States and in England. JAMA, 295, 2037-2045. doi: 10.1001/jama.295.17.2037 Bjartveit, K., \& Tverdal, A. (2003). Health consequences of smoking 1-4 cigarettes per day. Tobacco Control, 14, 315-320. doi: 10.1136/tc.2005.011932

Cho, H. J., Khang, Y. H., Jun, H. J., \& Kawachi, I. (2008). Marital status and smoking in Korea: The influence of gender and age. Social Science \& Medicine, 66, 609-619. doi: 10.1016/j.socscimed.2007.10.005

Dube, S. R., Asman, K., Malarcher, A., \& Carabollo, R. (2009). Cigarette Smoking Among Adults and Trends in Smoking Cessation - United States, 2008. MMWR. Morbidity and Mortality Weekly Report, 58(44), 1227-1232.

Health and Retirement Study. (2008a). Sample Sizes and Response Rates Retrieved 17 June, 2009, from http://hrsonline.isr.umich.edu/sitedocs/sampleresponse.pdf

Health and Retirement Study. (2008b). Wave 8/2006 public use dataset. Produced and distributed by the University of Michigan with funding from the National Institute on Aging (grant number NIA U01AG09740). Ann Arbor, MI: University of Michigan

Hitchman, S. C., \& Fong, G. T. (2011). Gender empowerment and female-to-male smoking prevalence ratios. Bulletin of the World Health Organization, 89, 195-202. doi: 10.2471/BLT.10.079905

Khang, Y.-H., Yun, S.-C., Cho, H.-J., \& Jung-Choi, K. (2009). The impact of governmental antismoking policy on socioeconomic disparities in cigarette smoking in South Korea. Nicotine \& Tobacco Research, 11(3), 262-269. doi: 10.1093/ntr/ntn036

Khang, Y. H., \& Cho, H. J. (2006). Socioeconomic inequality in cigarette smoking: Trends by gender, age, and socioeconomic position in South Korea, 1989-2003. Preventive Medicine, 42, 415-422. doi: 10.1016/j.ypmed.2006.02.010 
Kim, S. S., Son, H., \& Nam, K. A. (2005). Personal Factors Influencing Korean American Men's Smoking Behavior: Addiction, Health, and Age. Archives of Psychiatric Nursing, 19(1), 35-41. doi: 10.1016/j.apnu.2004.11.005

Korea Labor Institute. (2007). User Guide for 2007 KLoSA Retrieved 4 June 2009, from http://www.kli.re.kr:8080/klosa/en/about/introduce.jsp

Lee, H. Y. (2004). Divorce in Korea. International Medical Journal, 11, 194-199.

Lopez, A. D., Collishaw, N. E., \& Piha, T. (1994). A descriptive model of the cigarette epidemic in developed countries. Tobacco Control, 3, 242-247. doi: 10.1136/tc.3.3.242

Melbourne Institute of Applied Economic and Social Research. (2008). HILDA Survey Annual Report 2007. Melbourne: The University of Melbourne, Melbourne Institute of Applied Economic and Social Research.

Meyler, D., Stimpson, J. P., \& Peek, M. K. (2007). Health concordance within couples: A systematic review. Social Science \& Medicine, 64(11), 2297-2310. doi: 10.1016/j.socscimed.2007.02.007

National Health and Medical Research Council. (2009). Australian Guidelines to Reduce Health Risks from Drinking Alcohol. Canberra: NHMRC Publications.

National Institute on Alcohol Abuse and Alcoholism. (2008). Rethinking Drinking: Alcohol and Your Health. Bethesda, MD: National Institutes of Health, U.S. Dept. of Health and Human Services.

Organisation for Economic Co-operation and Development. (2008a). Growing Unequal? Income Distribution and Poverty in OECD Countries. Paris: OECD.

Organisation for Economic Co-operation and Development. (2008b). PPPs and exchange rates. Retrieved 4 June 2009, from Organisation for Economic Co-operation and Development http://stats.oecd.org/Index.aspx?datasetcode=SNA_TABLE4 
Pampel, F. C. (2006). Global Patterns and Determinants of Sex Differences in Smoking. International Journal of Comparative Sociology, 47(6), 466-487. doi: $10.1177 / 0020715206070267$

Park, E. J., Koh, H. K., Kwon, J. W., Suh, M. K., Kim, H., \& Cho, S. I. (2009). Secular trends in adult male smoking from 1992 to 2006 in South Korea: Age-specific changes with evolving tobacco-control policies. Public Health, 123(10), 657-664.

Prescott, E., Scharling, H., Osler, M., \& Schnohr, P. (2002). Importance of light smoking and inhalation habits on risk of myocardial infarction and all cause mortality. Journal of Epidemiology and Community Health, 56, 702-706. doi: 10.1136/jech.56.9.702

Schaap, M. M., Kunst, A. E., Leinsalu, M., Regidor, E., Espelt, A., Ekholm, O., et al. (2009). Female ever-smoking, education, emancipation and economic development in 19 European countries. Social Science \& Medicine, 68, 1271-1278. doi: 10.1016/j.socscimed.2009.01.007

Schone, B. S., \& Weinick, R. M. (1998). Health-related behaviors and the benefits of marriage for elderly persons. Gerontologist, 38, 618-627.

Scollo, M. M., \& Winstanley, M. H. (Eds.). (2008). Tobacco in Australia: Facts and Issues (Third ed.). Melbourne: Cancer Council Victoria.

Sulander, T., Helakorpi, S., Rahkonen, O., Nissinen, A., \& Uutela, A. (2004). Smoking and alcohol consumption among the elderly: trends and associations, 1985-2001. Preventive Medicine, 39(2), 413-418. doi: 10.1016/j.ypmed.2004.02.049,

U.S. Dept. of Health and Human Services. (2004). The Health Consequences of Smoking: A Report of the Surgeon General. Atlanta, GA: U.S. Dept. of Health and Human Services, Centers for Disease Control and Prevention, National Center for Chronic Disease Prevention and Health Promotion, Office on Smoking and Health Retrieved from http://www.cdc.gov/tobacco/data_statistics/sgr/2004/complete_report/index.htm. 
United Nations Development Programme. (2009). Human Development Report 2009;

Overcoming barriers: Human Mobility and Development. Basingstoke, Hampshire: Palgrave Macmillan.

United Nations Population Division. (2010). Population Ageing and Development 2009.

Retrieved 24 Jan 2012, from United Nations Population Division http://www.un.org/esa/population/publications/ageing/ageing2009.htm

United Nations Population Division. (2011). World Population Prospects: The 2010 Revision (Vol. II: Demographic Profiles ). New York: United Nations.

United Nations Statistics Division. (2007). Women’s Share of Tertiary Enrolment. Retrieved December 18, 2009 from United Nations Statistics Division http://data.un.org/Explorer.aspx?d=GenderStat.

Van Loon, A. J. M., Tijhuis, M., Picavet, H. S. J., Surtees, P. G., \& Ormel, J. (2003). Survey Non-response in the Netherlands: Effects on Prevalence Estimates and Associations. Annals of Epidemiology, 13(2), 105-110. doi: 10.1016/S1047-2797(02)00257-0

Wewers, M. E., Dhatt, R. K., Moeschberger, M. L., Guthrie, R. M., Kuun, P., \& Chen, M. S. (1995). Misclassification of smoking status among Southeast Asian adult immigrants. American Journal of Respiratory and Critical Care Medicine, 152, 1917-1921.

Wooden, M., Freidin, S., \& Watson, N. (2002). The Household, Income and Labour Dynamics in Australia (HILDA) Survey: Wave 1. Australian Economic Review 35(3), 339-348.

World Bank. (2011). Gross Domestic Product 2010 Retrieved Jan 24 2012, from http://siteresources.worldbank.org/DATASTATISTICS/Resources/GDP.pdf

World Health Organization. (2011a). WHO Report on the Global Tobacco Epidemic, 2011: Tobacco control country profiles Retrieved 24 Jan 2012, from World Health 


\section{Organization}

http://www.who.int/tobacco/surveillance/policy/country_profile/en/index.html

World Health Organization. (2011b). WHO Report on the Global Tobacco Epidemic, 2011:

Warning about the Dangers of Tobacco. Geneva: World Health Organization. 
Table 1. Demographic and health characteristics for males and females in Australia, the United States of America and South Korea, $2006^{\mathrm{a}}$

\begin{tabular}{|c|c|c|c|c|c|c|c|c|c|c|}
\hline \multirow[t]{2}{*}{ Characteristic } & \multicolumn{3}{|c|}{ Australia } & \multicolumn{3}{|c|}{ USA } & \multicolumn{3}{|c|}{ Korea } & \multirow[t]{2}{*}{$p \operatorname{diff}^{b}$} \\
\hline & Male & Female & Total & Male & Female & Total & Male & Female & Total & \\
\hline$\overline{\mathrm{N}}$ & 2525 & 2856 & 5381 & 7501 & 10734 & 18235 & 4286 & 5584 & 9870 & \\
\hline$\%$ & 46.9 & 53.1 & 100 & 41.4 & 58.9 & 100 & 43.4 & 56.6 & 100 & $<.001$ \\
\hline Age (\%) & & & & & & & & & & $<.001$ \\
\hline $45-54$ years & 38.9 & 37.6 & 38.2 & 9.4 & 12.2 & 11.1 & 32.6 & 31.7 & 32.1 & \\
\hline 55-64 years & 29.1 & 27.9 & 28.4 & 26.2 & 27.2 & 26.8 & 28.7 & 26.1 & 27.3 & \\
\hline $65-74$ years & 19.2 & 19.1 & 19.2 & 37.4 & 32.3 & 34.4 & 26.9 & 25.6 & 26.2 & \\
\hline 75-84 years & 11.2 & 12.7 & 12.0 & 20.5 & 18.8 & 19.5 & 10.3 & 13.6 & 12.2 & \\
\hline $85+$ years & 1.5 & 2.7 & 2.2 & 6.5 & 9.5 & 8.3 & 1.5 & 2.9 & 2.3 & \\
\hline Age (mean) & 59.8 & 60.7 & 60.3 & 68.3 & 68.2 & 68.2 & 61.1 & 62.2 & 61.7 & $<.001$ \\
\hline Partnered (\%) & 78.7 & 63.2 & 70.5 & 79.6 & 54.9 & 65.0 & 91.7 & 67.0 & 77.8 & $<.001$ \\
\hline Educational level (\%) & & & & & & & & & & $<.001$ \\
\hline Primary school or less & 3.5 & 4.1 & 3.8 & 6.4 & 5.4 & 5.8 & 29.8 & 57.6 & 45.5 & \\
\hline High school & 34.3 & 54.2 & 44.9 & 47.5 & 55.2 & 52.0 & 51.2 & 37.3 & 43.3 & \\
\hline Post-secondary & 41.9 & 23.1 & 31.9 & 20.0 & 21.6 & 20.9 & 2.4 & 0.8 & 1.5 & \\
\hline Completed degree & 20.3 & 18.6 & 19.4 & 26.1 & 17.9 & 21.3 & 16.6 & 4.3 & 9.7 & \\
\hline Net wealth USD 1000s (mean) & 447 & 417 & 431 & 430 & 349 & 382 & 138 & 128 & 133 & $<.001$ \\
\hline Self-rated health (\%) & & & & & & & & & & $<.001$ \\
\hline
\end{tabular}




\begin{tabular}{|c|c|c|c|c|c|c|c|c|c|c|}
\hline Poor & 5.3 & 5.4 & 5.4 & 8.2 & 9.6 & 9.0 & 19.4 & 30.7 & 5.8 & \\
\hline Fair & 19.1 & 19.9 & 19.5 & 20.8 & 21.2 & 21.2 & 24.8 & 28.5 & 26.9 & \\
\hline Good & 38.6 & 38.3 & 38.4 & 30.8 & 30.3 & 30.5 & 39.5 & 30.6 & 34.5 & \\
\hline Excellent/very good & 37.0 & 36.4 & 36.7 & 40.2 & 38.9 & 39.4 & 16.3 & 10.2 & 12.9 & \\
\hline Alcohol consumption & & & & & & & & & & $<.001$ \\
\hline Non-drinker & 13.9 & 23.8 & 19.2 & 41.9 & 56.8 & 50.7 & 38.5 & 84.4 & 64.5 & \\
\hline Light drinker & 50.0 & 60.4 & 55.5 & 42.8 & 38.2 & 40.1 & 28.9 & 13.4 & 20.2 & \\
\hline Moderate drinker & 20.5 & 11.7 & 15.8 & 9.1 & 3.9 & 6.0 & 13.3 & 1.4 & 6.5 & \\
\hline At-risk drinker & 15.6 & 4.1 & 9.5 & 6.2 & 1.1 & 3.2 & 19.3 & 0.8 & 8.8 & \\
\hline
\end{tabular}

${ }^{a}$ Values shown are unweighted; percentages may not sum to 100 due to rounding

${ }^{\mathrm{b}}$ Significance test of the difference in proportions (Chi squared) or means (Analysis of Variance) between country totals 
Table 2. Current smoking rates (95\% confidence intervals) for males and females in each age group in Australia, the United States of America and South Korea, 2006

\begin{tabular}{|c|c|c|c|c|c|c|}
\hline \multirow[b]{2}{*}{ Age group } & \multicolumn{2}{|c|}{ Australia } & \multicolumn{2}{|c|}{ United States of America } & \multicolumn{2}{|c|}{ Korea } \\
\hline & Male & Female & Male & Female & Male & Female \\
\hline 45-54 years & $26.0(23.0-29.3)$ & $20.6(17.7-23.9)$ & $23.4(19.3-28.1)$ & $17.9(14.5-21.8)$ & $50.4(47.6-53.3)$ & $2.8(2.1-3.8)$ \\
\hline 65-74 years & $12.4(9.4-16.2)$ & $8.1(6.0-10.9)$ & $12.9(11.4-14.5)$ & $12.3(10.9-13.9)$ & 34.2 (31.2 - 37.3) & $2.8(2.0-3.8)$ \\
\hline 75-84 years & $4.7(2.8-7.8)$ & $4.9(2.9-8.0)$ & $6.7(5.4-8.4)$ & $6.8(5.6-8.2)$ & $24.4(20.4$ - 28.8) & $5.4(3.9-7.6)$ \\
\hline Total & $18.2(16.6-20.0)$ & $13.9(12.4-15.6)$ & $16.2(15.1-17.5)$ & $13.2(12.1-14.3)$ & $42.7(41.0-44.4)$ & $3.1(2.6-3.6)$ \\
\hline National estimates $^{\mathrm{a}}$ & 22 & 19 & 33 & 25 & 49 & 7 \\
\hline
\end{tabular}

${ }^{\mathrm{a}}$ World Health Organization age-standardized estimated prevalence of cigarette smoking among those aged 15 years and older (World Health Organization, 2011a). 
Table 3. Odds ratios (95\% confidence intervals) of current smoking ${ }^{\mathrm{a}}$ in Australia, the United States of America and South Korea, 2006

\begin{tabular}{|c|c|c|c|c|c|c|}
\hline \multirow[t]{2}{*}{ Predictor (reference group) } & \multicolumn{2}{|c|}{ Australia } & \multicolumn{2}{|c|}{ USA } & \multicolumn{2}{|c|}{ Korea } \\
\hline & OR & $95 \% \mathrm{CI}$ & OR & $95 \% \mathrm{CI}$ & OR & $95 \% \mathrm{CI}$ \\
\hline Age (years) & $0.94 * * *$ & $0.94-0.95$ & $0.94 * * *$ & $0.94-0.95$ & $0.97 * * *$ & $0.96-0.98$ \\
\hline Gender (female) & $1.37^{* *}$ & $1.13-1.65$ & $1.30 * * *$ & $1.17-1.43$ & $22.68 * * *$ & $18.38-27.98$ \\
\hline Partner status (partnered) & $1.79 * * *$ & $1.47-2.19$ & $1.58 * * *$ & $1.36-1.85$ & $2.23 * * *$ & $1.78-2.79$ \\
\hline Wealth (quintiles) & $0.78 * * *$ & $0.72-0.85$ & $0.79 * * *$ & $0.74-0.83$ & $0.86 * * *$ & $0.82-0.91$ \\
\hline \multicolumn{7}{|l|}{ Education (completed degree) } \\
\hline Primary school or less & 1.19 & $0.58-2.45$ & 1.34 & $0.98-1.84$ & $1.80 * * *$ & $1.39-2.33$ \\
\hline High school & $1.78^{* * *}$ & $1.32-2.41$ & $2.25^{* * *}$ & $1.91-2.64$ & $1.35^{* *}$ & $1.10-1.66$ \\
\hline Post-secondary & 1.33 & $0.99-1.79$ & $1.84 * * *$ & $1.50-2.25$ & 1.31 & $0.82-2.09$ \\
\hline \multicolumn{7}{|c|}{ Self-rated health (very good/excellent) } \\
\hline Poor & $2.72 * * *$ & $1.74-4.23$ & $1.91 * * *$ & $1.56-2.33$ & 1.19 & $0.93-1.52$ \\
\hline Fair & $1.59 * *$ & $1.20-2.10$ & $1.68 * * *$ & $1.46-1.92$ & $1.33^{*}$ & $1.05-1.67$ \\
\hline Good & $1.65 * * *$ & $1.31-2.08$ & $1.35^{* * *}$ & $1.18-1.53$ & $1.36 * *$ & $1.12-1.66$ \\
\hline \multicolumn{7}{|c|}{ Alcohol consumption (light drinker) } \\
\hline Non-drinker & 0.81 & $0.62-1.07$ & 0.90 & $0.81-1.01$ & $0.40 * * *$ & $0.34-0.48$ \\
\hline Moderate drinker & $1.41^{* *}$ & $1.10-1.82$ & $1.94 * * *$ & $1.51-2.51$ & $1.41^{* *}$ & $1.13-1.75$ \\
\hline At-risk drinker & $2.48 * * *$ & $1.86-3.31$ & $3.20 * * *$ & $2.42-4.23$ & $1.35^{* *}$ & $1.10-1.65$ \\
\hline
\end{tabular}

a reference group is 'non-smokers' which includes never and former smokers; *** $\mathrm{p}<.001,{ }^{* *} \mathrm{p}<.01,{ }^{*} \mathrm{p}<.05$ 
Table 4. Odds ratios (95\% confidence intervals) of current smoking ${ }^{\mathrm{a}}$ for males and females in South Korea, 2006

\begin{tabular}{|c|c|c|c|c|}
\hline \multirow[t]{2}{*}{ Predictor (reference group) } & \multicolumn{2}{|r|}{ Males } & \multicolumn{2}{|r|}{ Females } \\
\hline & OR & $95 \% \mathrm{CI}$ & OR & $95 \% \mathrm{CI}$ \\
\hline Age (years) & $0.97 * * *$ & $0.96-0.97$ & 0.99 & $0.97-1.01$ \\
\hline Partner (partnered) & $1.75 * * *$ & $1.34-2.28$ & $2.51 * * *$ & $1.68-3.75$ \\
\hline Wealth (quintiles) & $0.89 * * *$ & $0.84-0.93$ & $0.65 * * *$ & $0.55-0.77$ \\
\hline \multicolumn{5}{|l|}{ Education (completed degree) } \\
\hline Primary school or less & $1.87 * * *$ & $1.43-2.44$ & 0.58 & $0.24-1.42$ \\
\hline High school & $1.49 * * *$ & $1.20-1.84$ & $0.29 * *$ & $0.12-0.72$ \\
\hline Post-secondary & 1.30 & $0.81-2.10$ & 0.79 & $0.17-3.71$ \\
\hline \multicolumn{5}{|c|}{ Self-rated health (very good/excellent) } \\
\hline Poor & 1.03 & $0.79-1.35$ & $2.28 *$ & $1.03-5.06$ \\
\hline Fair & $1.39 *$ & $1.08-1.78$ & 1.25 & $0.55-2.83$ \\
\hline Good & $1.39 * *$ & $1.14-1.70$ & 1.27 & $0.58-2.76$ \\
\hline \multicolumn{5}{|c|}{ Alcohol consumption (light drinker) } \\
\hline Non-drinker & $0.44 * * *$ & $0.36-0.53$ & $0.27 * * *$ & $0.18-0.41$ \\
\hline Moderate drinker & $1.39 * *$ & $1.11-1.74$ & 2.39 & $0.97-5.87$ \\
\hline At-risk drinker & $1.35 * *$ & $1.10-1.65$ & 2.25 & $0.75-6.70$ \\
\hline
\end{tabular}

